Supporting Information for

\title{
Molecularly Imprinted and Cladded Nanoparticles Provide Better Phosphorylation Recognition
}

Jialing Zhao, Hui He, Zhanchen Guo and Zhen Liu*

State Key Laboratory of Analytical Chemistry for Life Science, School of Chemistry and Chemical Engineering, Nanjing University, Nanjing 210023, China.

*Corresponding author: zhenliu@nju.edu.cn

\section{Contents}

- Supplementary Experimental Section

- Supplementary Figures

Figure S1 to Figure S13

- Supplementary Tables

Table S1

- Supplementary References 


\section{Supplementary Experimental Section}

\section{Materials and Methods}

Reagents and Materials. Triton X-100, adenosine (AD), deoxyadenosine (DA), cytidine (CT), adenosine monophosphate (AMP), cytidine monophosphate (CMP), deoxyadenosine monophosphate (DMP), trypsin, $\beta$-casein, phosphotyrosine (pTyr) and $\alpha$-cyano-4hydroxycinnamic acid (CHCA) were obtained from Sigma-Aldrich (St. Louis, MO, USA). NCetyltrimethyl ammonium bromide $(\mathrm{CTAB})$ and $\mathrm{Na}_{3} \mathrm{PO}_{4}$ were purchased from Macklin Biochemical (Shanghai, China). Cyclohexane, n-hexanol, acetone, 3-aminopropyltriethoxysilane (APTES), 3-ureidopropyltriethoxysilane (UPTES), benzyltriethoxysilane (BnTES), tetraethyl orthosilicate (TEOS), methanol triethylamine (TEA) and acetonitrile (ACN) were purchased from Aladdin (Shanghai, China). 1,4-Benzenebisphosphonic acid and p-xylylenebisphosphonic acid were obtained from TCI (Shanghai, China). Non-phosphorylated and phosphorylated peptides with HPLC purity $>$ 98\%, including GDEFDLG, DRVpSIHPF, DRVpTIHPF, DRVpYIHPF, DRVSIHPF, DRVTIHPF and DRVYIHPF were ordered from Top-Peptide Biotechnology (Shanghai, China). 1,4-Phenylenebisphosphoric acid was purchased from Psai Chemical Products (Henan, China). All other chemical reagents were of analytical grade unless otherwise stated. Water used in all experiments was purified by a Milli-Q Advantage A10 ultrapure water purification system (Millipore, Milford, MA, USA).

Instruments. Transmission electron microscopic (TEM) characterization was performed on a JEOL JEM-1011 TEM instrument (Tokyo, Japan). The UV absorbance measurement was performed on a NanoDrop 2000/2000C spectrophotometer (Thermo Fisher Scientific, Shanghai, China), and the wavelength was set at $260 \mathrm{~nm}$ for nucleotides or nucleosides and $214 \mathrm{~nm}$ for peptides. FT-IR spectra $\left(4000-400 \mathrm{~cm}^{-1}\right)$ in $\mathrm{KBr}$ were recorded on a Vector 22 spectrometer (Bruker, 
Germany). The X-ray photoelectron spectroscopy (XPS) analysis experiment was carried out on an XPS PHI1500VersProbe (ULVAC-PHI, Japan). Zeta-potential was measured on a BI-200SM instrument (Brookhaven Instrument Corporation, Holtsville, NY, USA). Matrix-assisted laser desorption/ionization time-of-flight mass spectrometric (MALDI TOF MS) analyses were carried out on a 4800 plus MALDI TOF/TOF Analyzer (Applied Biosystems, Framingham, MA, USA) with a pulsed nitrogen laser operated at $337 \mathrm{~nm}$. All mass spectra reported were obtained in the positive ion mode. The matrix for MALDI-TOF MS was $15 \mathrm{mg} / \mathrm{mL} \mathrm{CHCA} \mathrm{(for} \mathrm{peptides} \mathrm{analysis)}$ dissolved in $50 \%$ ACN containing $0.1 \%$ (v/v) TFA. Equivalent amounts $(1 \mu \mathrm{L})$ of the sample and matrix were sequentially dropped onto the MALDI plate for MALDI-TOF MS analysis.

Preparation of silica nanoparticles by CTAB-based reverse microemulsion system. The capability of CTAB single surfactant reverse microemulsion system to prepare monodisperse silica nanoparticles was first investigated. Silica nanoparticles were prepared according to the method described by Tam et al. ${ }^{[1]}$ with slight modifications. The procedure is schematically shown in Figure S1. Briefly, $100.0 \mathrm{~g}$ toluene, $6 \mathrm{~mL}$-butanol and $7.2 \mathrm{~g}$ CTAB were mixed and dispersed uniformly for $30 \mathrm{~min}$, and then $2 \mathrm{~mL}$ of ammonia water was added dropwise. After that, the mixture was added with $2 \mathrm{~g}$ TEOS and stirred at room temperature for $24 \mathrm{~h}$. Unfortunately, even after the optimization of the type of oil phase and the amount of CTAB, amorphous material rather than monodisperse silica nanoparticles was obtained (Figure S2).

\section{Preparation of silica nanoparticles by CTAB \& Triton X-100-based dual-surfactant reverse} microemulsion system. The possibility using CTAB \& Triton X-100-based dual-surfactant system to produce monodispersed silica nanoparticles was investigated. The procedure is schematically 
shown in Figure S3. 1.77 g Triton X-100, 7.5 mL cyclohexane and $1.6 \mathrm{~mL}$-hexanol were mixed in a $25-\mathrm{mL}$ eggplant-shaped flask, and then a certain amount of CTAB $(2 \mathrm{~g}, 1.5 \mathrm{~g}, 1 \mathrm{~g}, 500 \mathrm{mg}$, $100 \mathrm{mg}, 10 \mathrm{mg}, 5 \mathrm{mg}, 2 \mathrm{mg}$ or $1 \mathrm{mg})$ was added. After that, water $(480 \mu \mathrm{L})$ and ammonium hydroxide (100 $\mu \mathrm{L}, 28 \% \mathrm{wt})$ were dripped into solution subsequently and stirred for $30 \mathrm{~min}$. Next, tetraethyl orthosilicate (TEOS, $100 \mu \mathrm{L}$ ) was added and stirred for $24 \mathrm{~h}$. The prepared nanomaterials were released from the microemulsion by adding acetone $(10 \mathrm{~mL})$ and stirred for $30 \mathrm{~min}$. The suspensions were centrifuged at 4,000 rpm for $30 \mathrm{~min}$ and the supernatant were removed. The collected nanoparticles were washed with anhydrous ethanol and deionized water three times each and then freeze-dried in a vacuum overnight.

Optimization of imprinting conditions of anti-p-cMIPs and anti-pY-cMIPs. The specific ratio between total monomer and TEOS used for the preparation of cMIPs were optimized in terms of the obtained imprinting factor (IF). For anti-p-cMIPs, considering the template $\left(\mathrm{Na}_{3} \mathrm{PO}_{4}\right)$ has no UV absorbance, adenosine monophosphate (AMP) was chosen as the test compound for this investigation. Equivalent (2 mg each) anti-p-cMIPs and cNIPs prepared at different specific molar ratios of monomers and cross-linker (APTES, UPTES, and TEOS) were added separately to $1 \mathrm{~mL}$ of incubation solution $\left(\mathrm{ACN}: \mathrm{H}_{2} \mathrm{O}=80: 20, \mathrm{v} / \mathrm{v}\right)$ containing $1 \%$ TEA and $1 \mathrm{mg} / \mathrm{mL}$ AMP. The tube was shaken on a rotator for $60 \mathrm{~min}$ at room temperature. The nanoparticles were collected by centrifugation and then washed with $500 \mu \mathrm{L}$ of above solution $\left(\mathrm{ACN}: \mathrm{H}_{2} \mathrm{O}=80: 20, \mathrm{v} / \mathrm{v}\right.$, containing $1 \%$ TEA) three times. After that, the nanoparticles were re-suspended and eluted in $20 \mu \mathrm{L}$ of $\mathrm{MeOH}: \mathrm{H}_{2} \mathrm{O}: \mathrm{HCl}=50: 49: 1(\mathrm{v} / \mathrm{v} / \mathrm{v})$ at room temperature for $60 \mathrm{~min}$ on a rotator. Finally, the suspensions were centrifuged at 4,000 rpm for $30 \mathrm{~min}$ and the supernatant were collected. The amount of AMP was determined by measuring the UV absorbance of the supernatant at $260 \mathrm{~nm}$. 
The measurement was repeated three times. For optimization of phosphate imprinted MIPs and NIPs, all the procedures were the same as described above except that anti-p-cMIPs and cNIPs were replaced by phosphate imprinted MIPs and NIPs, respectively.

For anti-pY-cMIPs, the procedure was almost the same, expect that phosphotyrosine (pTyr) was chosen as the test compound because of its structure and UV chromophoric group. Equivalent (2 mg each) anti-pY-cMIPs and cNIPs prepared with different template and at different specific molar ratios of monomers and cross-linker (APTES, UPTES, BnTES and TEOS) were added separately to $1 \mathrm{~mL}$ of incubation solution (ACN: $\mathrm{H}_{2} \mathrm{O}=80: 20$, v/v, containing $1 \%$ TEA) containing $1 \mathrm{mg} / \mathrm{mL}$ pTyr. The rest processes were the same as anti-p-cMIPs. The amounts of phosphotyrosine extracted by nanoparticles were evaluated by measuring the UV absorbance at $220 \mathrm{~nm}$.

Measurement of dissociation constant and binding capacity. The molecularly imprinted and cladded nanoparticles (cMIPs) at the optimized monomer ratio described above were selected for binding capacity and dissociation constant investigation. For details, equivalent amount ( $2 \mathrm{mg}$ each) of anti-p-cMIPs or anti-pY-cMIPs and corresponding cNIPs were dispersed into $1 \mathrm{~mL}$ standard solution of target compound (AMP or pTyr) of known concentration $(0.1,0.2,0.3,0.4,0.5,0.6$, 0.7 or $0.8 \mathrm{mg} / \mathrm{mL}$ ) and the mixtures were shaken on a rotator for $1 \mathrm{~h}$ at room temperature. After that, the suspensions were centrifuged at 4,000 rpm for $30 \mathrm{~min}$ and the supernatant were removed. After washing and elution as described above, the eluates were detected to estimate the binding affinity of anti-p-cMIPs. The amount of target compound (AMP or pTyr) bound by the anti-pcMIPs or anti-pY-cMIPs were plotted according to the Scatchard equation as given below:

$$
Q_{\mathrm{e}} /[S]=\left(Q_{\max }-Q_{\mathrm{e}}\right) / K_{\mathrm{d}}
$$

where $Q_{\mathrm{e}}$ was amounts of the target bound to imprinted material at equilibrium, $[S]$ was the free 
concentration of targets at equilibrium, $Q_{\max }$ was the maximum specific binding capacity, and $K_{\mathrm{d}}$ was the dissociation constant. The measurement was repeated for three parallel experiments.

Selectivity of anti-p-cMIPs and anti-p Y-cMIPs. The selectivity of anti-p-cMIPs was evaluated using the nucleotides, adenosine (AD), deoxyadenosine (DA), cytidine (CT), adenosine monophosphate (AMP), cytidine monophosphate (CMP) and deoxyadenosine monophosphate (DMP). First, each nucleotide standard solution $(1 \mathrm{mg} / \mathrm{mL})$ was separately prepared with incubation solution ( $1 \%$ TEA dissolved in $\left.\mathrm{ACN}: \mathrm{H}_{2} \mathrm{O}=80: 20, \mathrm{v} / \mathrm{v}\right)$. Then, equivalent corresponding anti-p-cMIPs and cNIPs ( $2 \mathrm{mg}$ each) were added to $1 \mathrm{~mL}$ of the above solutions in 1.5-mL centrifugal tubes. The tubes were shaken on a rotator at room temperature for $60 \mathrm{~min}$. The nanoparticles were collected by centrifugation at $4,000 \mathrm{rpm}$ for $30 \mathrm{~min}$ and rinsed with $500 \mu \mathrm{L}$ of washing solution ( $1 \%$ TEA dissolved in $\left.\mathrm{ACN}: \mathrm{H}_{2} \mathrm{O}=80: 20, \mathrm{v} / \mathrm{v}\right)$ three times. After that, the nanoparticles were re-suspended and eluted in $20 \mu \mathrm{L}$ of MeOH: $\mathrm{H}_{2} \mathrm{O}: \mathrm{HCl}=50: 49: 1(\mathrm{v} / \mathrm{v} / \mathrm{v})$ at room temperature for $60 \mathrm{~min}$ on a rotator. Finally, the nanoparticles were precipitated via centrifugation and the supernatant were collected. The amount of nucleotides bound by the anti-p-cMIPs/cNIPs was determined by measuring the UV absorbance of the supernatant at $260 \mathrm{~nm}$. The measurement was repeated three times.

For the selectivity test of anti-pY-cMIPs, all the procedure was the same as described above except that the test compounds were changed to DRVpSIHPF (pS), DRVpTIHPF (pT), DRVpYIHPF (pY), DRVSIHPF (S), DRVTIHPF (T) and DRVYIHPF (Y) and that the washing step was carried out with $500 \mu \mathrm{L}$ of ACN: $\mathrm{H}_{2} \mathrm{O}=80: 20$ (v/v, containing $1 \%$ TEA) and with $500 \mu \mathrm{L}$ of $\mathrm{ACN}: \mathrm{H}_{2} \mathrm{O}=$ 50:50 ( $\mathrm{v} / \mathrm{v}$, containing $1 \%$ TEA) for three times each. The amount of peptides bound by the antipY-cMIPs/cNIPs was determined by measuring the UV absorbance of the supernatant at $214 \mathrm{~nm}$. 


\section{Supplementary Figures}

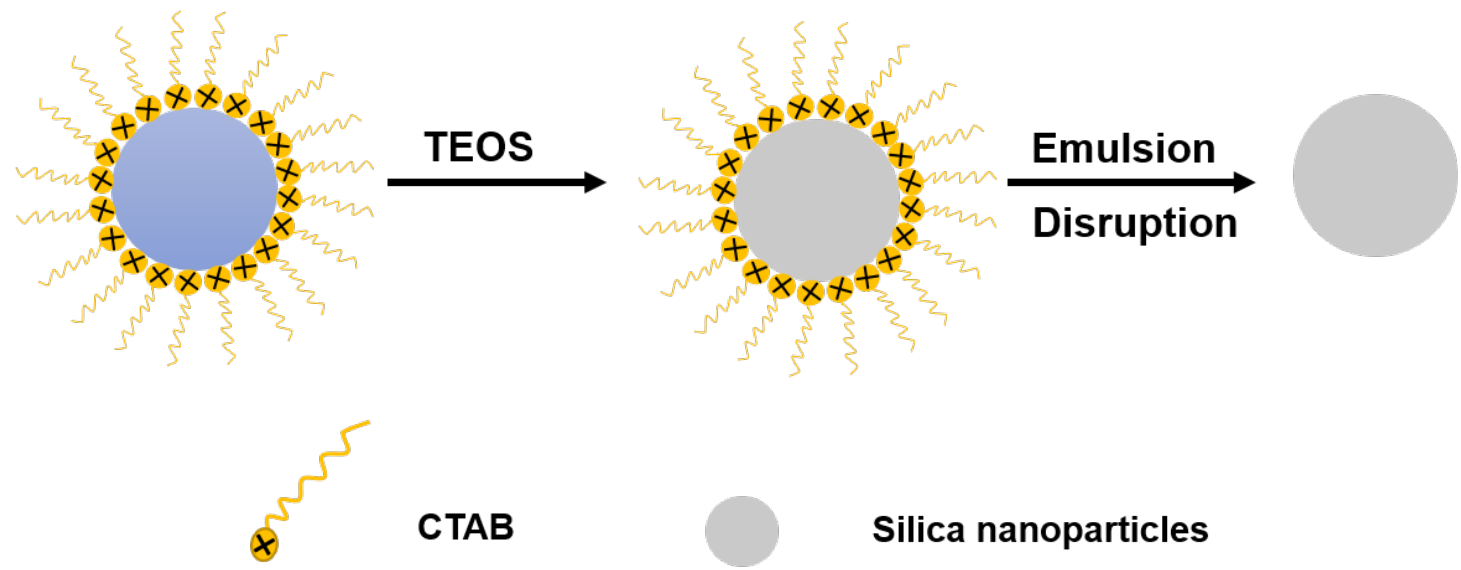

Figure S1. Schematic of the synthesis route of silica nanoparticles by CTAB reverse microemulsion system. 

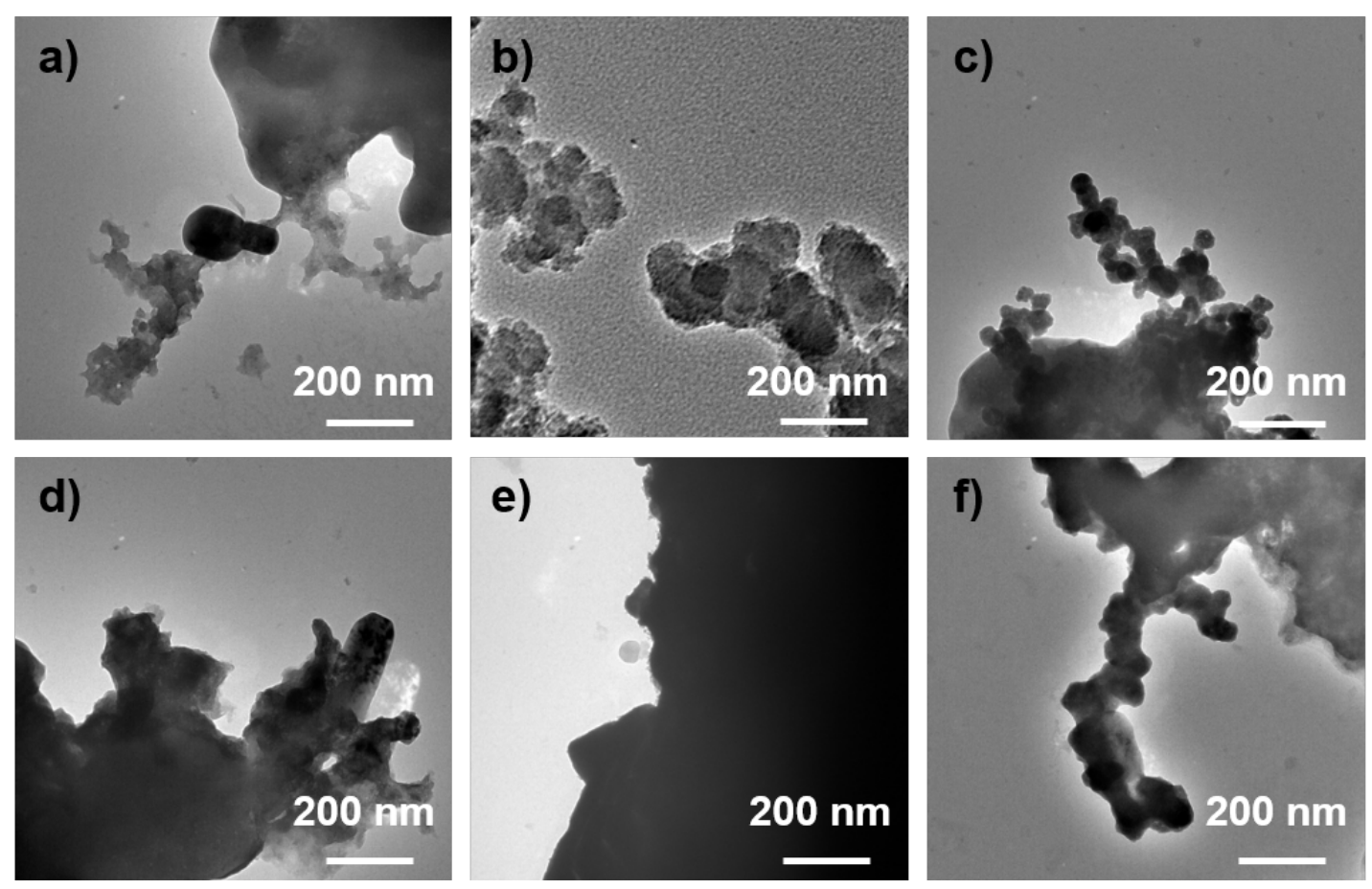

Figure S2. TEM images of the materials prepared by CTAB reverse microemulsion. 


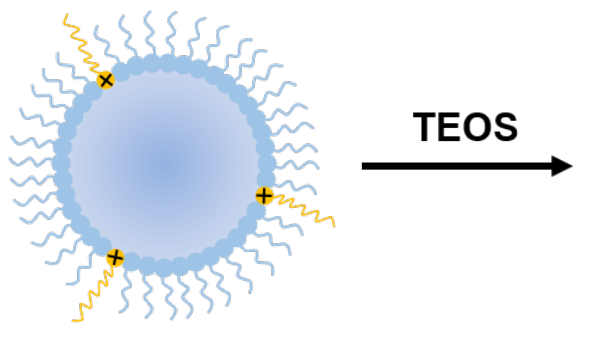

Triton $X-100 \quad x$

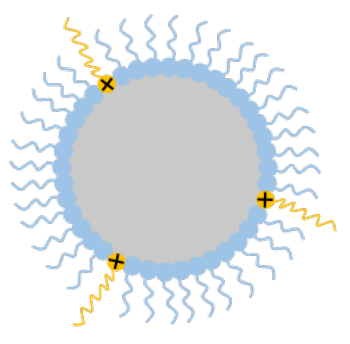

CTAB

\section{$\underset{\text { Disruption }}{\stackrel{\text { Emulsion }}{\longrightarrow}}$}

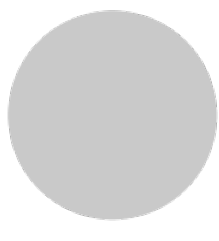

Silica nanoparticles

Figure S3. Schematic of the synthesis of silica nanoparticles by CTAB \& Triton X-100-based dual-surfactant reverse microemulsion system. 

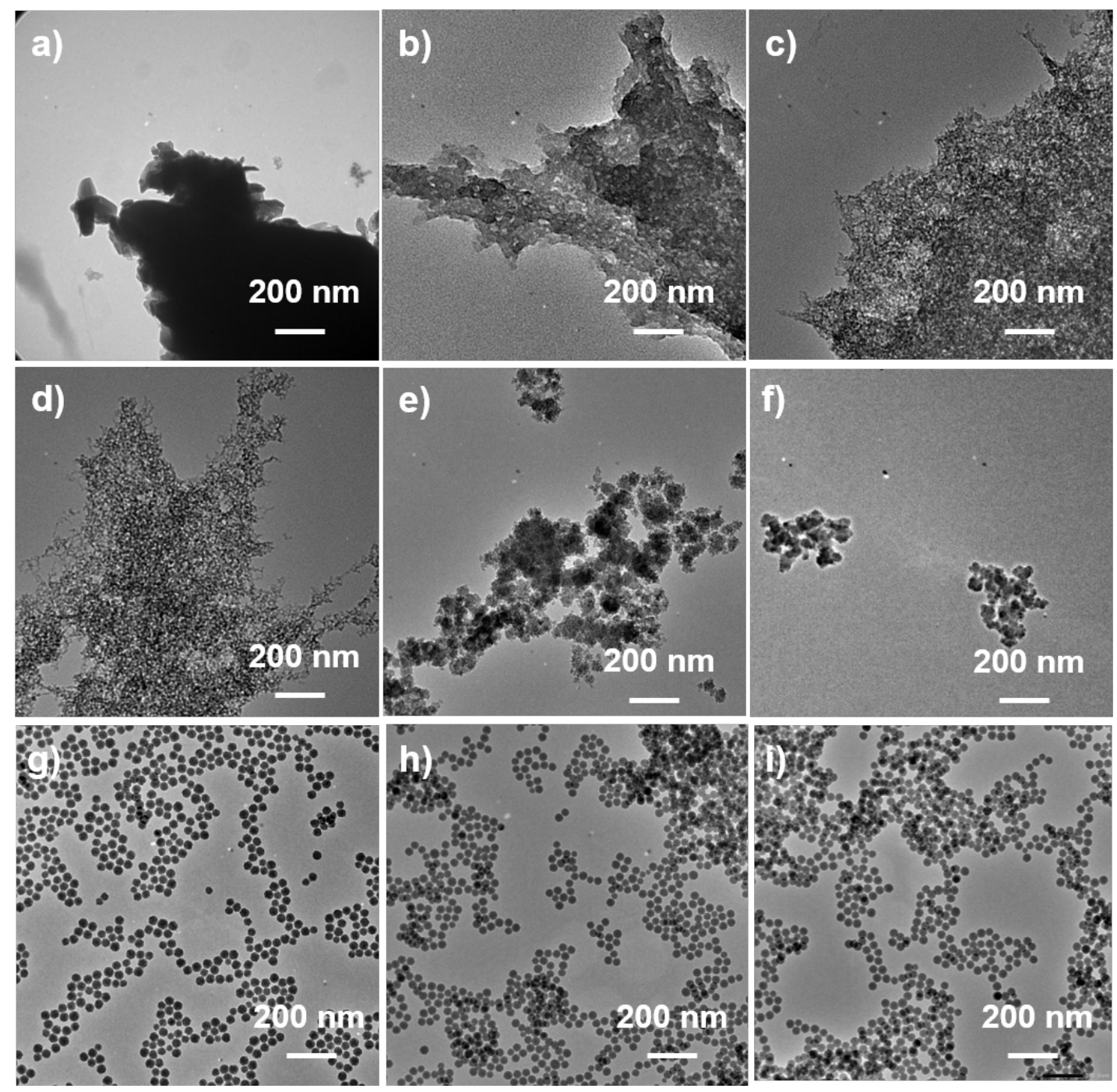

Figure S4. TEM images of the materials prepared by the dual-surfactant reverse microemulsion system of CTAB and Triton X-100. a)-i) the amount of CTAB was $2 \mathrm{~g}, 1.5 \mathrm{~g}$, $1 \mathrm{~g}, 500 \mathrm{mg}, 100 \mathrm{mg}, 10 \mathrm{mg}, 5 \mathrm{mg}, 2 \mathrm{mg}$ and $1 \mathrm{mg}$, respectively (with co-existence of $1.77 \mathrm{~g}$ Triton X-100, $7.5 \mathrm{~mL}$ cyclohexane $1.6 \mathrm{~mL}$-hexanol and $480 \mu \mathrm{L}$ water). 


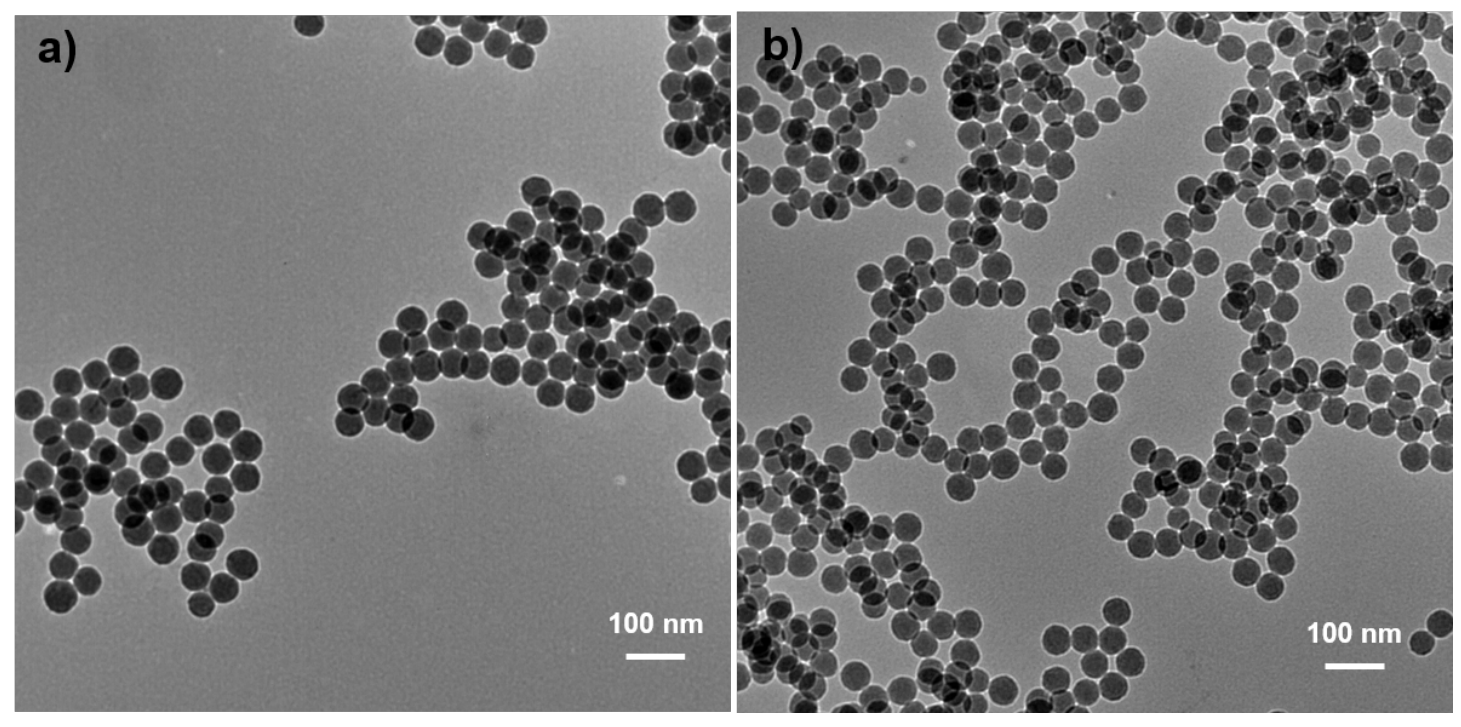

Figure S5. TEM images of (a) phosphate-imprinted nanoparticles (MIP) and (b) phosphateimprinted and cladded nanoparticles (cMIP) prepared at the ratio of APTES:UPTES:TEOS = 2:3:95 by CTAB \& Triton X-100-based dual-surfactant reverse microemulsion system. 


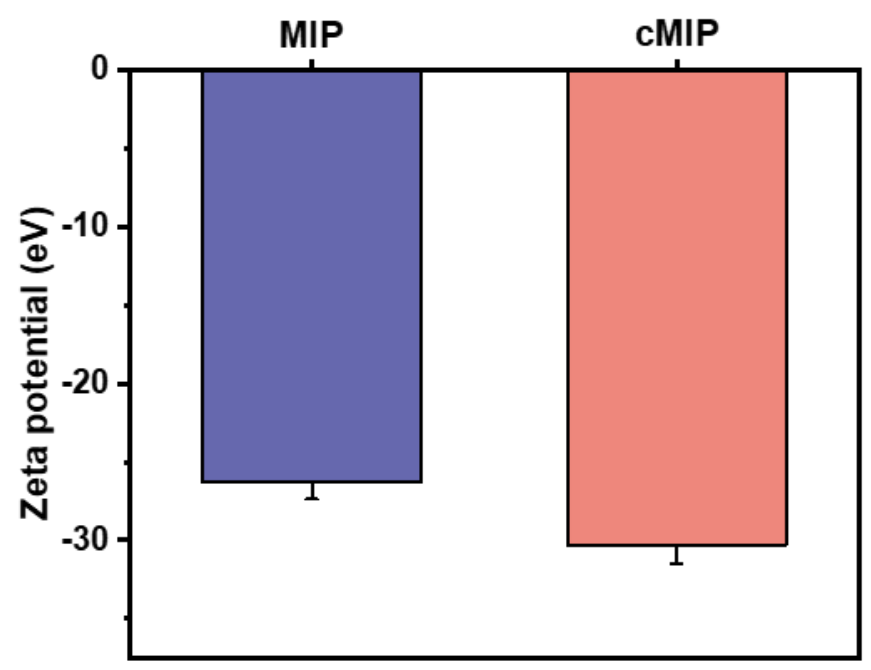

Figure S6. Zeta potential of phosphate-imprinted MIP and cMIP nanoparticles in water. 


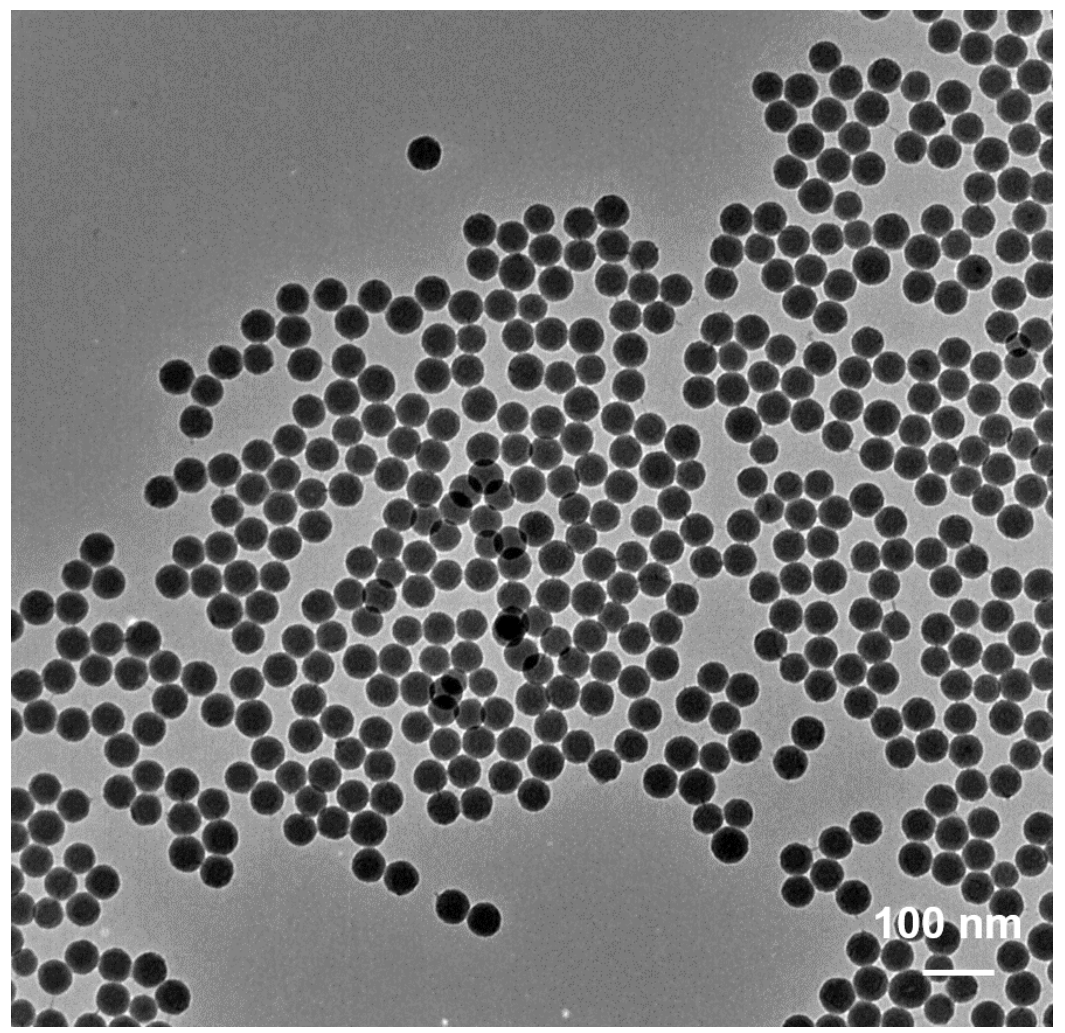

Figure S7. TEM image of non-imprinted and cladded nanoparticles (cNIP) corresponding to anti-p-cMIP prepared at the ratio of APTES:UPTES:TEOS $=2: 3: 95$ by CTAB \& Triton X100-based dual-surfactant reverse microemulsion system. 

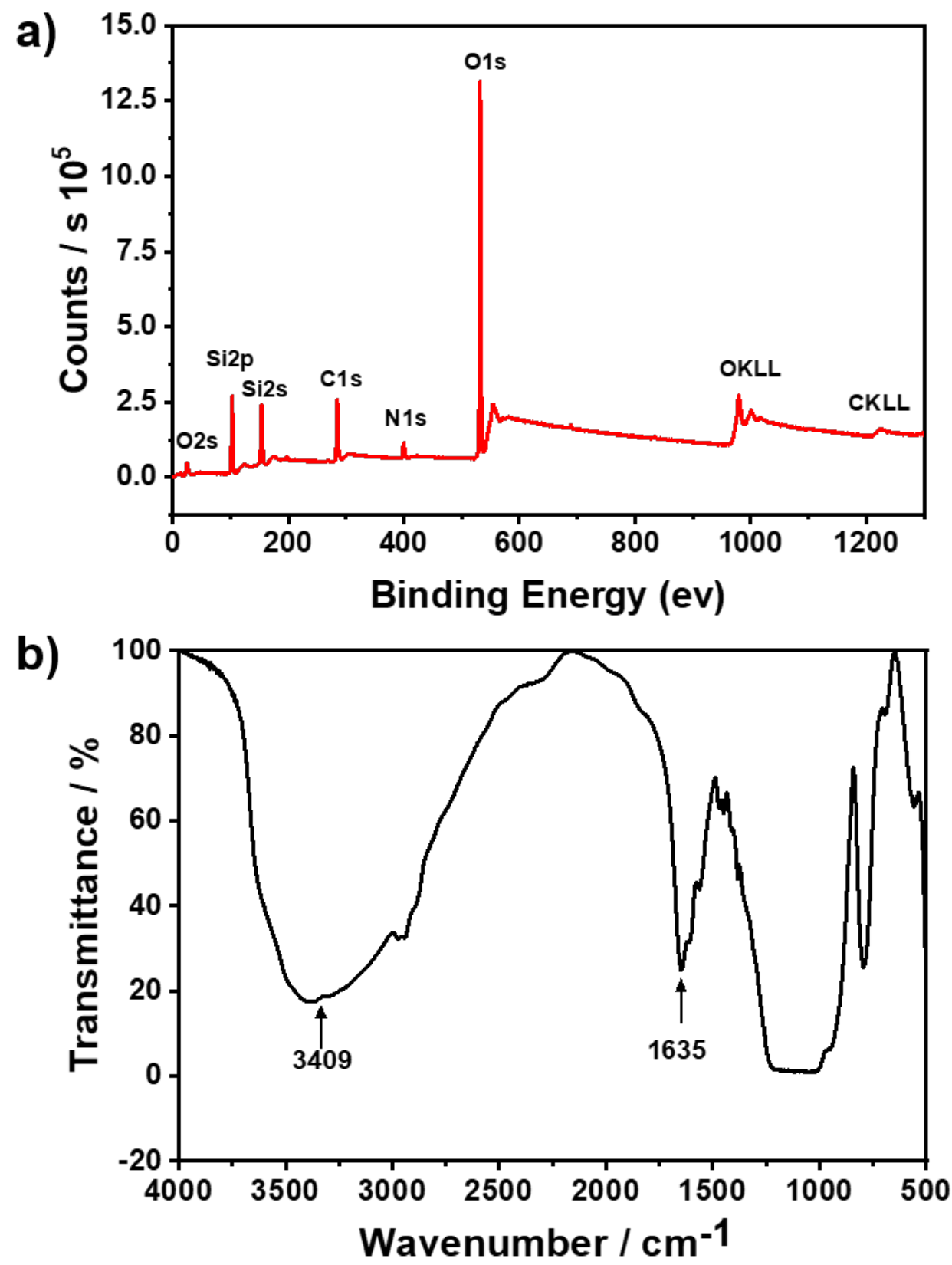

Figure S8. (a) XPS spectra and (b) FT-IR spectra of anti-p-cMIP prepared at the ratio of APTES:UPTES:TEOS $=2: 3: 95$ by CTAB \& Triton X-100-based dual-surfactant reverse microemulsion system.. 
a)

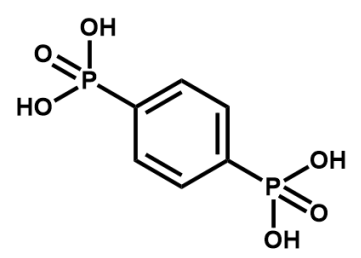

b)

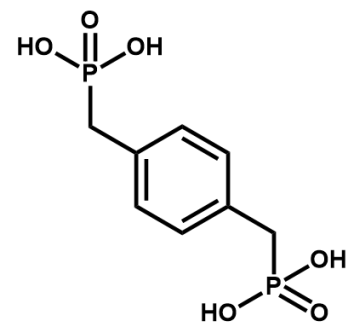

c)

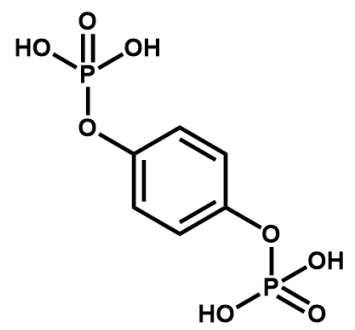

Figure S9. The structures of dummy templates used for the preparation of anti-pY-cMIP nanoparticles. a) 1,4-benzenebisphosphonic acid, b) p-xylylenebisphosphonic acid, c) 1,4phenylenebisphosphoric acid. 


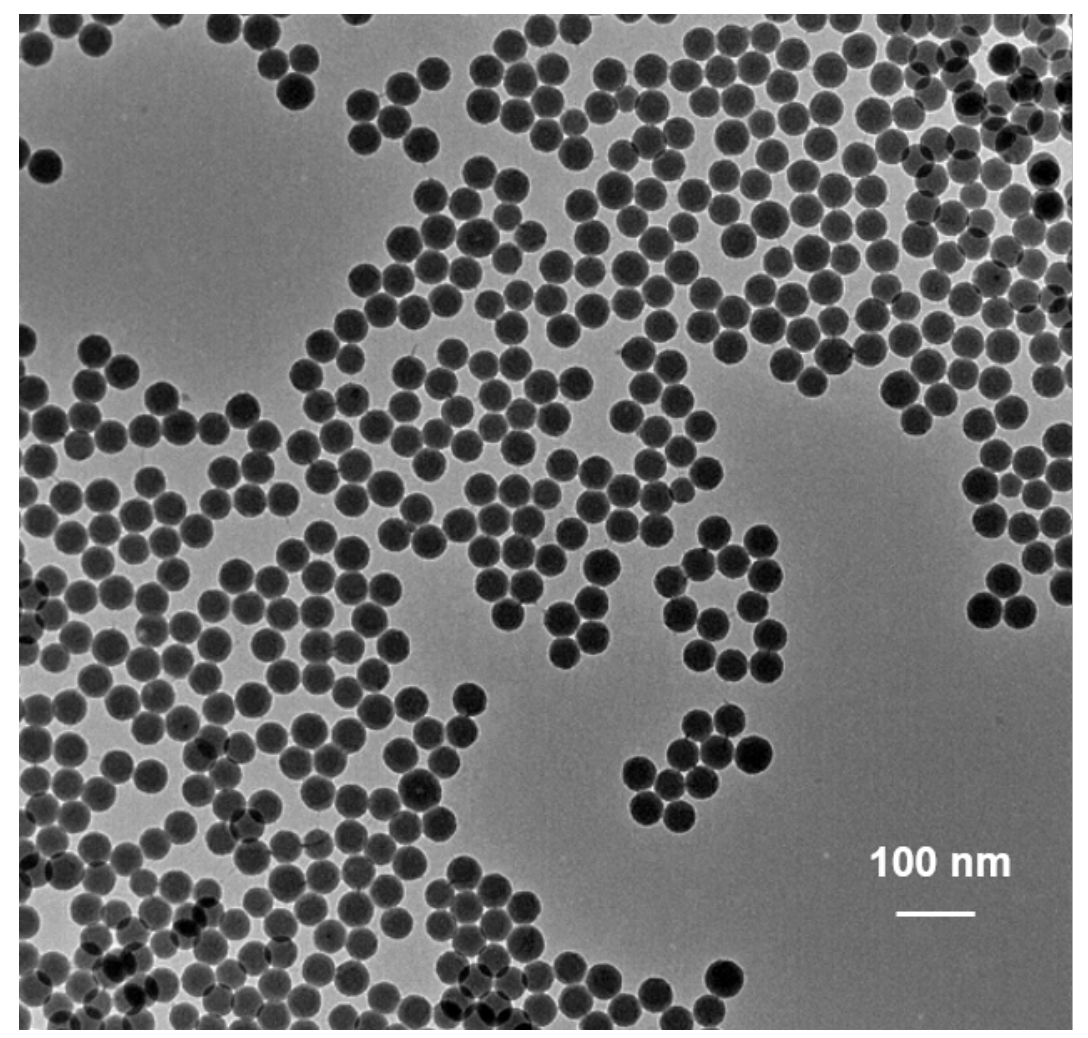

Figure S10. TEM image of non-imprinted and cladded nanoparticles (cNIP) corresponding to anti-pY-cMIP prepared at the ratio of APTES:UPTES:BnTES:TEOS $=2: 3: 5: 95$ by CTAB \& Triton X-100-based dual-surfactant reverse microemulsion system. 

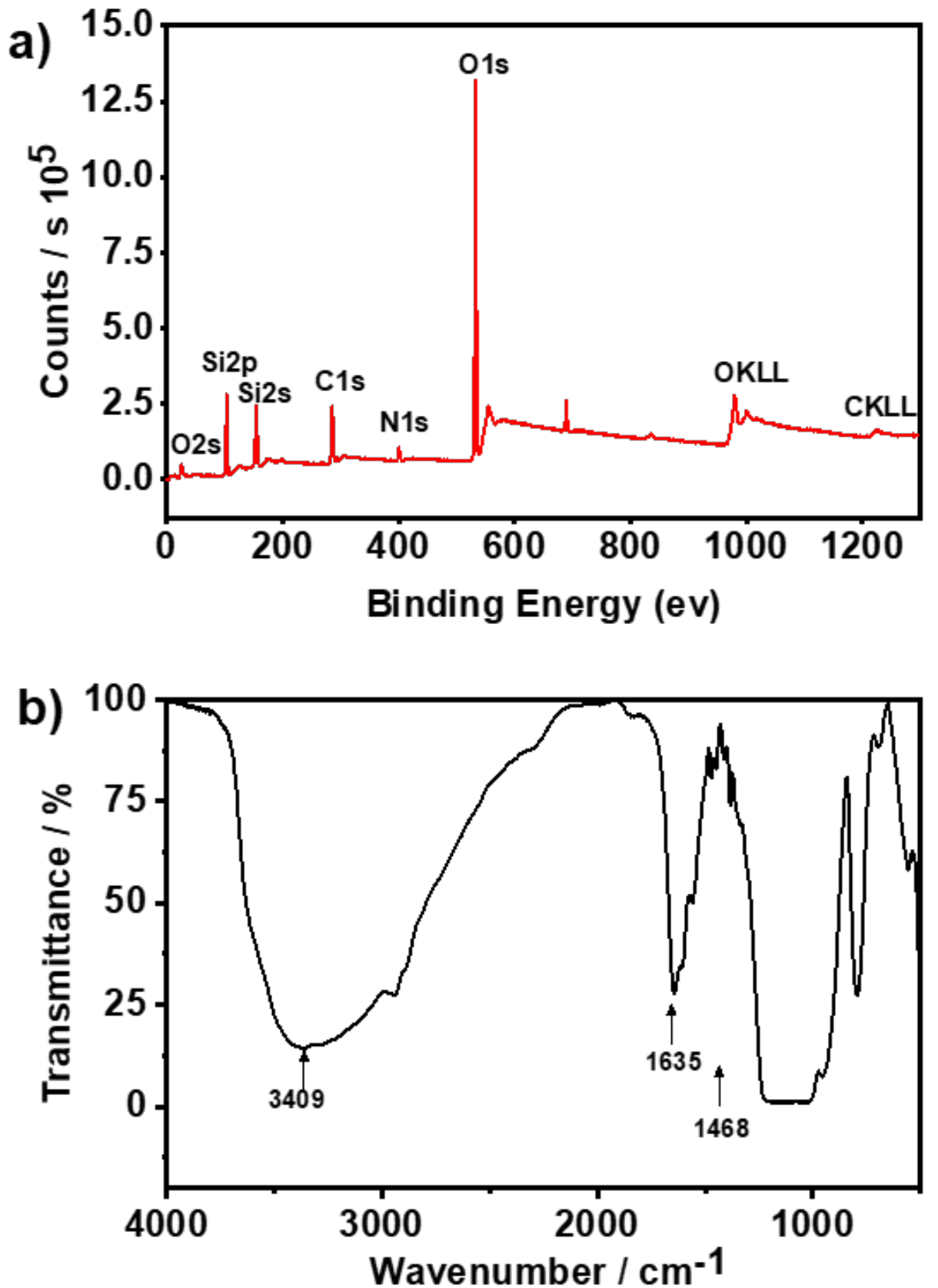

Figure S11. (a) XPS spectra and (b) FT-IR spectra of anti-pY-cMIP (template, 1,4phenylenebisphosphoric acid) prepared at the ratio of APTES:UPTES:BnTES:TEOS = 2:3:5:95 by CTAB \& Triton X-100-based dual-surfactant reverse microemulsion system. 

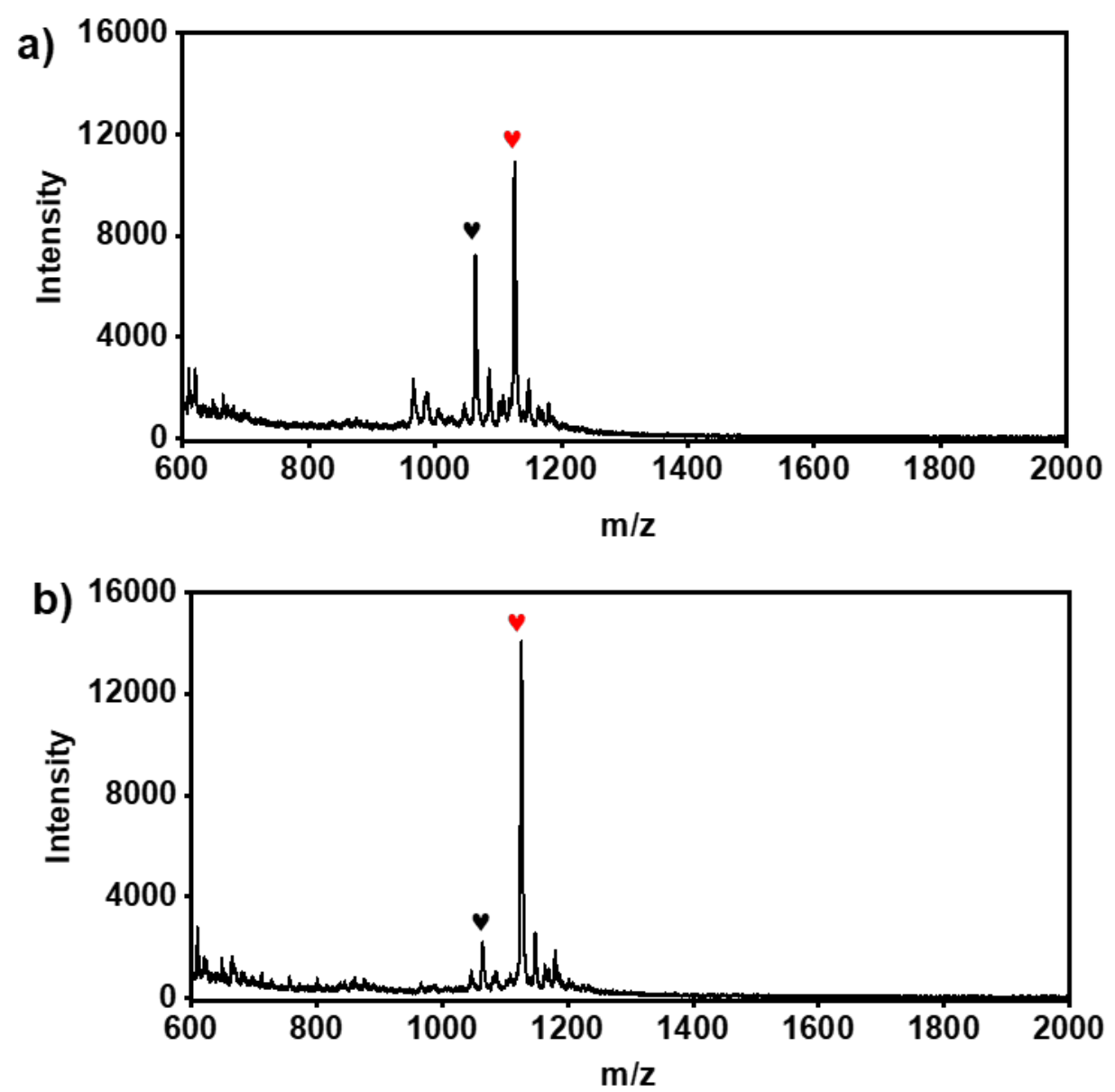

Figure S12. MALDI-TOF mass spectra. a) Direct analysis and b) analysis after enrichment by anti-pY-cMIPs. Sample: a peptide mixture containing DRVpYIHPF (red heart, $\mathrm{m} / \mathrm{z}=1125.84$ for $[\mathrm{M}+\mathrm{H}]^{+}$) and DRVpTIHPF (black heart, $\mathrm{m} / \mathrm{z}=1063.66$ for $\left.[\mathrm{M}+\mathrm{H}]^{+}\right)(1: 1, \mathrm{w} / \mathrm{w})$. 

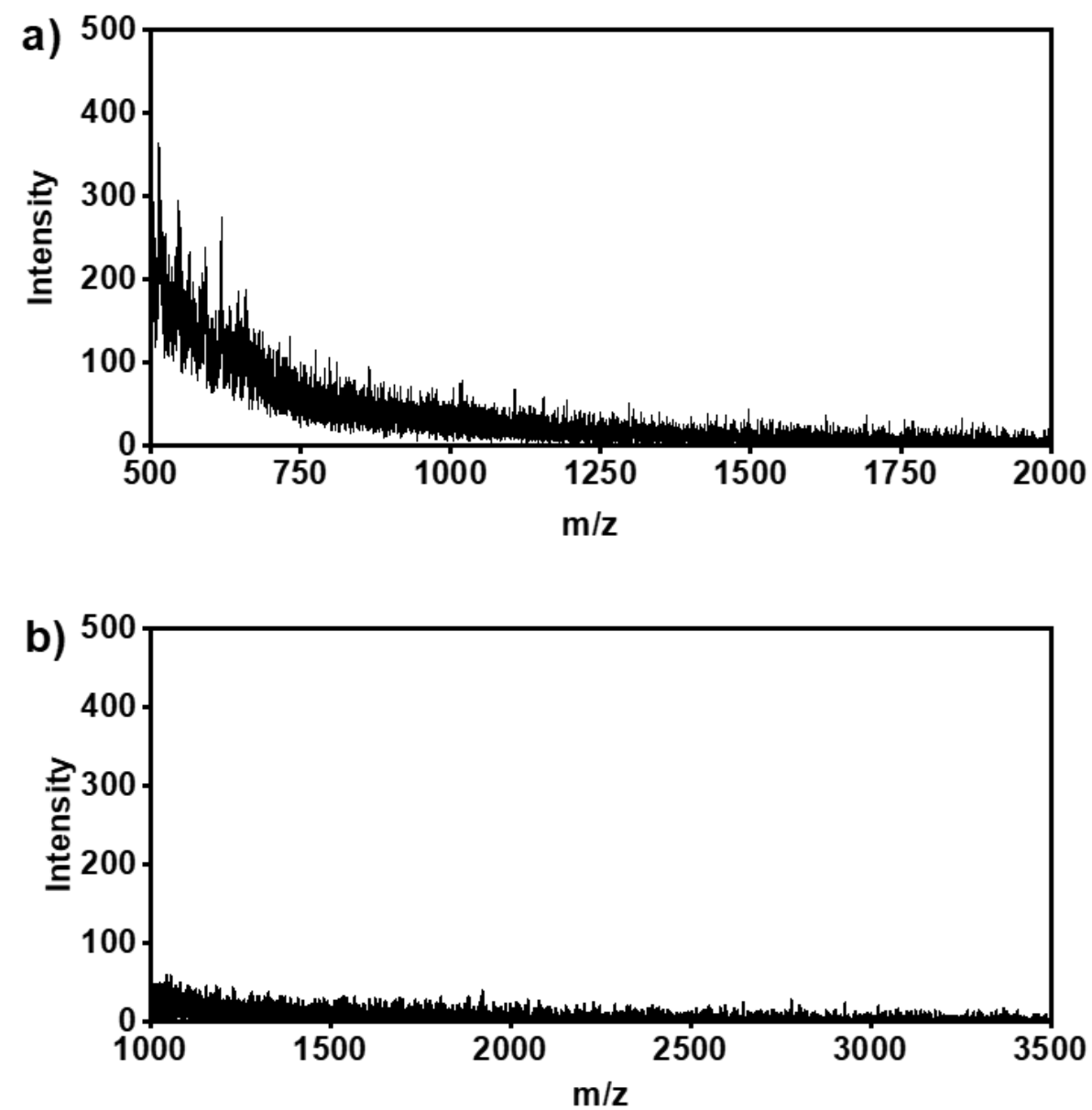

Figure S13. MALDI-TOF mass spectra of the eluates from cNIP after incubating with peptide mixture. Sample: a) the mixture containing DRVpTIHPF and GDEFDLG $(1: 100, w / w) ; b)$ the mixture containing DRVpYIHPF and tryptic digest of $\beta$-casein $(1: 100, w / w)$. 


\section{Supplementary Tables}

Table S1. Comparison of reported MIPs and their performance for phosphorylation recognition.

\begin{tabular}{|c|c|c|c|c|c|c|c|}
\hline Strategy & Target $^{a}$ & Template & Monomer & Morphology & IF & $K_{\mathrm{a}}$ & Ref. \\
\hline $\begin{array}{l}\text { Surface } \\
\text { imprinting }\end{array}$ & $\mathrm{pY}$ & PPA & guanidine monomer & xerogels & $1.3^{\mathrm{b}}$ & $10^{3} \mathrm{M}^{-1}$ & 3 \\
\hline \multirow{4}{*}{$\begin{array}{l}\text { Bulk epitope- } \\
\text { imprinting }\end{array}$} & $\mathrm{pY}$ & Fmoc-pTyrOEt & $\begin{array}{l}\text { urea-based host } \\
\text { monomer }\end{array}$ & $\begin{array}{l}\text { crushed monoliths } \\
25-36 \mu \mathrm{m}\end{array}$ & I & $10^{5} \mathrm{M}^{-1}$ & $2,4,5$ \\
\hline & pS & Fmoc-pSerOEt & $\begin{array}{l}\text { urea-based host } \\
\text { monomer }\end{array}$ & $\begin{array}{l}\text { crushed monoliths } \\
36-50 \mu \mathrm{m}\end{array}$ & I & I & 6 \\
\hline & $\mathrm{pY}$ & PPA & Zinc acrylate & crushed monoliths & 4.8 & I & 7 \\
\hline & $\mathrm{pY}$ & PPA & $\mathrm{Ti}^{4+}-\mathrm{EGMP}$ & $\begin{array}{l}\text { crushed monoliths } \\
1-5 \mu \mathrm{m}\end{array}$ & 2.5 & I & 8 \\
\hline \multirow{2}{*}{ DTD-OMI } & $\mathrm{p}$ & $\mathrm{PO}_{4}^{3-}$ & urea monomer & $\begin{array}{c}\text { mesoporous } \\
\text { nanoparticles } \\
190 \mathrm{~nm}\end{array}$ & 5.2 & $10^{5} \mathrm{M}^{-1}$ & 9 \\
\hline & $\mathrm{pY}$ & PPA & urea monomer & $\begin{array}{c}\text { mesoporous } \\
\text { nanoparticles } \\
70 \mathrm{~nm}\end{array}$ & 4.6 & $10^{3} \mathrm{M}^{-1}$ & 10 \\
\hline \multirow{2}{*}{ RMTD-SIC } & $\mathrm{p}$ & $\mathrm{PO}_{4}^{3-}$ & $\begin{array}{l}\text { urea and amino } \\
\text { monomers }\end{array}$ & $\begin{array}{c}\text { nonodisperse } \\
\text { nanoparticles } 50 \mathrm{~nm}\end{array}$ & 5.7 & $10^{4} \mathrm{M}^{-1}$ & $\begin{array}{l}\text { This } \\
\text { work }\end{array}$ \\
\hline & $\mathrm{pY}$ & BBPPA/ХBPPA/PBPPA & $\begin{array}{l}\text { Urea, amino and benzyl } \\
\text { monomers }\end{array}$ & $\begin{array}{c}\text { monodisperse } \\
\text { Nanoparticles } 45 \mathrm{~nm}\end{array}$ & 6.7 & $10^{4} M^{-1}$ & $\begin{array}{l}\text { This } \\
\text { work }\end{array}$ \\
\hline
\end{tabular}

${ }^{a} \mathrm{pY} / \mathrm{pS}$, phosphotyrosine or phosphoserine containing compounds. $\mathrm{p}$, phosphate containing

compounds.

${ }^{\mathrm{b}}$ Estimated from the data reported. 


\section{Supplementary References}

1. Tsang, S. C.; Yu, C.; Gao, X.; Tam, K. J. Phys. Chem. B. 2006, 110, 16914-16922.

2. Emgenbroich, M.; Vilela, F.; Courtois, J.; Borrelli, C.; Hall, A. J.; Simanova, A.; Shinde, S.; Oxelbark, J.; Verhage, J.; Lorenzi, D. E.; Irgum, K.; Lazraq, I.; Karim, K.; Sellergren, B. Chem. Eur. J. 2008, 14, 9516-9529.

3. Shea K. J. In Molecular and Ionic Recognition with Imprinted Polymers. ch 22, 1998, pp 314323.

4. Helling, S.; Shinde, S.; Brosseron, F.; Schnabel, A.; Meyer, H. E.; Marcus, K.; Sellergren, B. Anal. Chem. 2011, 83, 1862-1865.

5. Wan, W.; Descalzo, A. B.; Shinde, S.; Weisshoff, H.; Orellana, G.; Sellergren, B.; Rurack, K. Chem. Eur. J. 2017, 23, 15974-15983.

6. Chen1, J.; Shinde, S.; Koch, M.-H.; Sellergren, B. Sci. Rep. 2015, 5, 11438.

7. Li, Q. S.; Shen, F.; Zhang, X.; Hu, Y. F.; Ren, X. Q. Anal. Chim. Acta. 2013, 795, 82-7.

8. Xu, L.; Hu, Y. F.; Shen, F.; Li, Q. S.; Ren, X. Q. J. Chromatogr. A. 2013, 1293, 85-91.

9. Chen, Y.; Li, D. J.; Bie, Z. J.; He, X. P.; Liu, Z. Anal. Chem. 2016, 88, 1447-1454.

10. Zhang, G.; Jiang, L.; Hu, L. H.; Feng, S. Y. Chem. Commun. 2019, 55, 9927-9930. 